\title{
Genetics of seed dormancy in Papaver rhoeas
}

\author{
M. D. LANE \& M. J. LAWRENCE* \\ Wolfson Laboratory for Plant Molecular Biology, School of Biological Sciences, University of Birmingham, \\ Birmingham B15 2TT, U.K.
}

\begin{abstract}
Seed dormancy in a cross between wild Papaver rhoeas and its 'Shirley' cultivar appeared to be controlled by genes that displayed additive effects, dominance in the direction of low dormancy and non-allelic interaction of the duplicate type; in addition, there was a small maternal dominance effect in the direction of high dormancy. The genetics of seed dormancy in this cross is as predicted on Mather's theory of genetical architecture for a character that has been subject to strong directional selection. During the breeding of 'Shirley' poppies, at least six flower colour mutations were obtained in less than 20 years in a population whose effective size must have been very small. It is argued that, in view of the difficulty of detecting heritable variation for seed dormancy in wild poppies and the rarity of flower colour variants in wild $P$. rhoeas, it is possible that seed of the 'Shirley' cultivar lacks the dormancy of its wild ancestors because of mutation of one or two genes.
\end{abstract}

Keywords: directional selection, genetical architecture, Papaver rhoeas, seed dormancy, 'Shirley' cultivar.

\section{Introduction}

It was suggested in a previous paper (Lawrence \& Franklin-Tong, 1994) that the unequal frequencies of some of the self-incompatibility $(S-)$ alleles in natural populations of Papaver rhoeas (Campbell \& Lawrence, 1981; Lawrence \& O'Donnell, 1981) might be caused by linkage of the $S$-gene to one or more genes that control seed dormancy. There is no doubt that seed dormancy in this species is a heritable character because seed of the 'Shirley' cultivar lacks the pronounced innate dormancy of that of wild plants. Harper \& McNaughton (1960) investigated the inheritance of dormancy in a number of inter- and intraspecific crosses between species of the genus Papaver. Their results from a $P$. rhoeas cross, 'Shirley' $\times$ wildtype, obtained by germinating the seed at $15^{\circ} \mathrm{C}$ in the dark, showed some partial dominance in the direction of high germination and, in particular, a very large difference between the reciprocal $F_{1}$ crosses, indicating substantial maternal control over seed germination (Table 2). None of their crosses, however, was advanced beyond the $F_{1}$ generation. The purpose of the experiment described in the present paper was to obtain further information about the genetics of seed dormancy in $P$. rhoeas from the 16 families of the basic generations originating from the 'Shirley' $\times$ wild-type cross.

\footnotetext{
*Correspondence.
}

\section{Materials and methods}

The wild-type parents $\left(\mathrm{P}_{2}\right)$ of the cross were raised from seed of the R102 Family 9 (Lawrence \& FranklinTong, 1994) and the 'Shirley' parents $\left(\mathbf{P}_{1}\right)$ from a family derived from the 'Shirley' cultivar marketed by Suttons, Torquay, UK. The 'Shirley' family was segregating for three and the Family 9 for four $S$-alleles. The individuals of these families, however, can be regarded as true-breeding with respect to genes controlling seed dormancy. Two crosses were made in reciprocal between these parents so as to obtain $F_{1}$ progenies containing different incompatibility genotypes. In the following season, crosses were made in duplicate between plants both within and between the parental families and their $F_{1}$ progeny to obtain the full set of 16 families of the basic generations (Table 1). The number of replicates of each of these 16 families was determined by the desire to include as many combinations of the parental $S$-alleles in these progenies as possible. Further details of the composition of these families are given in Lane \& Lawrence (1995). In addition, two flowers on each of the plants used to produce these families were self-pollinated to test their self-incompatibility. Two capsules that had developed from openpollinated flowers were also harvested from each plant to find out whether emasculation had any adverse effect on seed quality or quantity. The self-pollinated capsules contained either no seed or a very small quantity of very poor quality seed, indicating that the 
plants were either completely or very nearly selfincompatible. All of the plants used to produce the seed were raised in the summer in open ground, as experience has shown that the quality of seed produced in this way is superior to that produced by plants raised out of season under glass. In all, 376 capsules were produced from controlled crosses in the main experiment and an additional 38 from open pollinations.

Seed from harvested capsules was cleaned in the usual way by passing it through two sieves, the first having 20 and the second 40 holes per inch, the latter retaining good seed, and was then stored at room temperature $\left(\cong 20^{\circ} \mathrm{C}\right)$ in the dark in small paper envelopes. The total weight of seed produced by each capsule and also the weight of 100 randomly chosen seeds were obtained to investigate the possibility that germination percentage is influenced by seed weight or seed quantity.

The majority of crosses in the main experiment were represented by seed from each of a pair of capsules as intended. Where, however, there was insufficient seed from one capsule, seed from the other was used as a substitute. If there were insufficient seed in both, the cross was excluded from the experiment. A small number of packets contained seed that appeared to be of poor quality. Experience has shown, however, that a visual assessment of quality is not always reliable, so that this seed was not initially excluded from the experiment.

The dormancy of each seed lot was tested by germinating 50 seeds, arranged in a $7 \times 7$ matrix plus one, on 'Carlson' filter pads (grade 4; $36 \mathrm{~mm}$ diameter, presterilized at $100^{\circ} \mathrm{C}$ for $60 \mathrm{~min}$ ) placed in sterile $60 \mathrm{~mm}$ plastic Petri dishes. These filter pads have a dimpled texture on one side and their thickness allows enough water to be added to a dish, both of which minimize the displacement of seeds during the trial. Seeds were placed, one by one, on the surface of the moistened filter pads with a grade 0 sable paintbrush.

A seed was scored as having germinated when its radicle had fully emerged, after which it was removed from the dish by a pair of fine forceps. Although the distribution of days to germination varied with the provenance of the seed, very little if any further germination occurred after 14 days, at which time the experiment was terminated. All of the seed used in these experiments was less than 12 months old. It was assumed, therefore, that any seed which failed to germinate during this 14-day period was dormant, rather than inviable and that it could, accordingly, have been induced to germinate had it received the customary dormancy-breaking treatment (Lawrence \& Franklin-Tong, 1994). No problems were experienced with contamination of any of the seed lots by fungal growth. Further details of materials and methods are given by Lane (1990).

\section{Results}

\section{Two preliminary trials}

McNaughton \& Harper (1964) investigated the effect of a number of treatments on the germination of wildtype $P$. rhoeas seed but found that only one, cold treatment for 2 days at $5^{\circ} \mathrm{C}$, increased germination percentage. This was not, however, the treatment (constant $15^{\circ} \mathrm{C}$ ) that they used in the experiment mentioned earlier (Harper \& McNaughton, 1960). Two small-scale preliminary trials were carried out, therefore, in an attempt to determine a suitable treatment for the main experiment. In the first of these trials seed was incubated at a constant temperature of $25^{\circ} \mathrm{C}$. In the second, seed was first allowed to imbibe water at $25^{\circ} \mathrm{C}$ for $24 \mathrm{~h}$ before being incubated at $2^{\circ} \mathrm{C}$ for 7 days and then brought back to a temperature of $25^{\circ} \mathrm{C}$ to score percentage germination. The second treatment was similar to that routinely used in this laboratory to break the dormancy of wild-type seed, except that the preliminary pulse treatment of dry seed with concentrated sulphuric acid before incubation was omitted (Lawrence \& Franklin-Tong, 1994). Thirty-two lots of 50 seed were tested in each trial which consisted of duplicate samples from each of two capsules of each of two reciprocal crosses of $\mathrm{P}_{1}, \mathrm{P}_{2}, \mathrm{~F}_{1(1 \times 2)}$ and $\mathrm{F}_{1(2 \times 1)}$. The results obtained from these trials are shown in Table 2 .

There are four points worth making about these results. First, the results obtained appear to depend on the conditions in which the seed was incubated, as those obtained from these trials differ not only from each other, but also from those obtained by Harper \& McNaughton (1960). Secondly, although the difference between the germination percentages of seed of the reciprocal $F_{1} s$ in the first trial is large, analysis of variance of these data transformed into angles (data not shown) revealed that this difference was not significant in either trial. Thirdly, the average germination percentage of the $F_{1} s$ differed significantly from the average of their parents in the second trial, indicating the presence of dominance in the direction of high germination percentage in these conditions. Fourthly, the empirical estimate of sampling variation, the mean square concerning differences between duplicate seed lots within capsules, was reassuringly very similar in both trials to the expected binomial sampling variance, which suggested that some economy of effort could be achieved in the main experiment by using only one sample of 50 seeds from each capsule. 
Table 1 Families of the basic generations of the cross between the 'Shirley' cultivar $\left(\mathrm{P}_{1}\right)$ and wild-type Papaver rhoeas $\left(\mathrm{P}_{2}\right)$

\begin{tabular}{lcccc}
\hline $\begin{array}{l}\text { Parents } \\
\text { Males } \rightarrow \\
\text { Females } \downarrow\end{array}$ & $\mathrm{P}_{1}$ & $\mathrm{~F}_{1(1 \times 2)}$ & $\mathrm{F}_{1(2 \times 1)}$ & $\mathrm{P}_{2}$ \\
\hline $\mathrm{P}_{1}$ & $\mathrm{P}_{1}$ & $\mathrm{~B}_{1}$ & $\mathrm{~B}_{1}$ & $\mathrm{~F}_{1}$ \\
& 12 & 12 & 12 & 24 \\
$\mathrm{~F}_{1(1 \times 2)}$ & $\mathrm{RB}_{1}$ & $\mathrm{~F}_{2}$ & $\mathrm{~F}_{2}$ & $\mathrm{RB}_{2}$ \\
& 12 & 16 & 16 & 48 \\
$\mathrm{~F}_{1(2 \times 1)}$ & $\mathrm{RB}_{1}$ & $\mathrm{RF}_{2}$ & $\mathrm{RF}_{2}$ & $\mathrm{RB}_{2}$ \\
$\mathrm{P}_{2}$ & 12 & 16 & 16 & 48 \\
& $\mathrm{RF}_{1}$ & $\mathrm{~B}_{2}$ & $\mathrm{~B}_{2}$ & $\mathrm{P}_{2}$ \\
& 24 & 48 & 48 & 12 \\
\hline
\end{tabular}

The numbers in the body of the table show the original number of replicate capsules of seed for each family.

Table 2 Results obtained from two preliminary germination trails with Papaver rhoeas

\begin{tabular}{lccc}
\hline Family & Trial 1 & Trial 2 & $\begin{array}{c}\text { Harper \& } \\
\text { McNaughton }\end{array}$ \\
\hline $\mathrm{P}_{1}$ & $97.8 \pm 0.8$ & $96.8 \pm 1.1$ & $76.0 \pm 1.4$ \\
$\mathrm{P}_{2}$ & 0 & $8.8 \pm 2.8$ & 0 \\
$\mathrm{~F}_{1(1 \times 2)}$ & $57.8 \pm 8.7$ & $97.8 \pm 0.7$ & $73.7 \pm 1.7$ \\
$\mathrm{~F}_{1(2 \times 1)}$ & $71.0 \pm 7.8$ & $92.8 \pm 1.9$ & $23.3 \pm 2.0$ \\
\hline
\end{tabular}

Entries in the second and third columns of the table show mean percentage germination $( \pm S E)$, each based on eight lots of 50 seeds. Harper \& McNaughton's (1960) results are shown in the fourth column for comparison.

As the differences among the average germination percentages of the four families were greater in the first trial than in the second, it was decided to incubate the seed of the main experiment at a constant $25^{\circ} \mathrm{C}$.

\section{Main experiment}

Fifty-eight of the original total of 376 capsules produced by hand-crossing contained insufficient seed to be used in the experiment, reducing this total to 318 . All of the 38 open-pollinated capsules, however, contained sufficient seed. The total number of dishes scored in the experiment was therefore 356 . While the range of germination percentages observed was, as expected, very great, the seed from eight capsules gave a very low percentage which was clearly out of line with that of the seed of other crosses in the same family. Furthermore, as the hundred seed weight of these capsules was also lower than that of other entries in these families, these outliers were excluded from the analysis of these data. It was possible to substitute the score obtained from the duplicate crosses for four of these capsules, but four had to be excluded from the experiment, because both duplicates were poor. The final number of dishes in the experiment was 352 consisting of 314 containing seed from hand-crosses and 38 containing open-pollinated seed. Further details of this exclusion procedure are given in Lane (1990). The number of dishes, and average germination percentage, total weight of seed, hundred seed weight and number of seeds per capsule for each of the 16 families in the experiment are shown in Table 3.

There are three points worth making about these results. First, the average germination percentages of $F_{1(1 \times 2)}$ and $F_{1(2 \times 1)}$ are much closer to those obtained in the second preliminary trial than to those of the first (Table 2). Although the number of $F_{1}$ families in each of the preliminary trials was half or less than half of the number in the main experiment, these discrepancies are too large to ascribe to chance. They suggest that the conditions in which seed is incubated may be less important than the conditions in which seed is stored or even, perhaps, the time of year when the experiment is carried out, because of seasonal fluctuations of dormancy (Harper, 1977). The preliminary trials were carried out in October and the main experiment in June of the following year.

Secondly, inspection of the entries in Table 3 suggests that there might be an association between germination percentage and the other seed characters. Correlation coefficients between the proportion of germinated seed (calculated after angular transformation of the data) and the other seed characters revealed, however, that there was very little evidence for this possibility. Thus, there was no overall correlation, calculated by pooling the data from individual capsules over families, between the proportion of seed that had germinated and either average weight of or number of seeds contained in a capsule. Furthermore, when correlation coefficients were calculated on the data of each family separately, in only one family were any of these coefficients significant. There was, however, a small $(r=0.124)$, but highly significant overall correlation between proportion of germinated seed and one hundred seed weight. This outcome is largely a consequence of the very large number of degrees of freedom of this coefficient because only four of the 16 correlation coefficients calculated on the data for each family separately were significant, three of these being positive and one negative. As these family correlations were significantly heterogeneous and, overall, no more than $r^{2}=1.5$ per cent of the variation of the proportion of germinated seed can be ascribed to one hundred 
seed weight, the former can be regarded as essentially independent of the latter.

Thirdly, a comparison of hand-pollinated with openpollinated capsules (Table 4) shows that, on average, the total and hundred seed weight, and the number of seeds per capsule are a little higher for the former. This comparison is not very exact, however, both because $\mathrm{B}_{2}$ progenies are more numerous in the main experiment than they are likely to be among the progeny of open-pollinated capsules and because the latter were the product of flowers that were borne on these plants later in the flowering season than the former. Neverthe-

Table 3 Summary of the results obtained from the main experiment concerning seed characters of Papaver rhoeas

\begin{tabular}{|c|c|c|c|c|c|}
\hline $\begin{array}{l}\text { Parents } \\
\text { Males } \rightarrow \\
\text { Females } \downarrow\end{array}$ & Key to entries in table & $\mathbf{P}_{1}$ & $F_{1(1 \times 2)}$ & $F_{1(2 \times 1)}$ & $\mathrm{P}_{2}$ \\
\hline $\mathrm{P}_{1}$ & $\begin{array}{l}\text { Family } \\
\text { No. of capsules } \\
\text { Mean germination }(\%) \\
\text { Mean seed weight/capsule } \\
\text { Mean } 100 \text { seed weight } \\
\text { Mean no. seeds/capsule }\end{array}$ & $\begin{array}{c}\mathrm{P}_{1} \\
8 \\
96.0 \pm 2.5 \\
187 \pm 30 \\
17.1 \pm 0.8 \\
1154 \pm 239\end{array}$ & $\begin{array}{c}\mathrm{B}_{1} \\
12 \\
97.0 \pm 0.9 \\
140 \pm 27 \\
16.0 \pm 0.6 \\
871 \pm 169\end{array}$ & $\begin{array}{c}\mathrm{B}_{1} \\
12 \\
95.3 \pm 1.4 \\
139 \pm 22 \\
14.9 \pm 0.8 \\
961 \pm 163\end{array}$ & $\begin{array}{c}F_{1} \\
16 \\
92.3 \pm 2.6 \\
135 \pm 20 \\
15.9 \pm 0.9 \\
921 \pm 146\end{array}$ \\
\hline$F_{1\{3 \times 2\}}$ & $\begin{array}{l}\text { Family } \\
\text { No. of capsules } \\
\text { Mean germination }(\%) \\
\text { Mean seed weight/capsule } \\
\text { Mean } 100 \text { seed weight } \\
\text { Mean no. seeds/capsule }\end{array}$ & $\begin{array}{c}\mathrm{RB}_{1} \\
10 \\
87.2 \pm 5.0 \\
154 \pm 23 \\
15.7 \pm 1.1 \\
1066 \pm 210\end{array}$ & $\begin{array}{c}\mathrm{F}_{2} \\
14 \\
53.0 \pm 4.4 \\
175 \pm 24 \\
16.0 \pm 0.7 \\
1117 \pm 157\end{array}$ & $\begin{array}{c}\mathrm{F}_{2} \\
16 \\
50.5 \pm 4.5 \\
171 \pm 15 \\
15.9 \pm 0.5 \\
1099 \pm 111\end{array}$ & $\begin{array}{c}\mathrm{RB}_{2} \\
44 \\
38.9 \pm 5.1 \\
140 \pm 9 \\
15.6 \pm 0.6 \\
996 \pm 77\end{array}$ \\
\hline$F_{1(2 \times 1)}$ & $\begin{array}{l}\text { Family } \\
\text { No. of capsules } \\
\text { Mean germination }(\%) \\
\text { Mean seed weight/capsule } \\
\text { Mean } 100 \text { seed weight } \\
\text { Mean no. seeds/capsule }\end{array}$ & $\begin{array}{c}\mathrm{RB}_{1} \\
12 \\
90.0 \pm 2.4 \\
149 \pm 19 \\
13.3 \pm 0.9 \\
1113 \pm 143\end{array}$ & $\begin{array}{c}\mathrm{RF}_{2} \\
16 \\
55.9 \pm 4.8 \\
159 \pm 19 \\
13.3 \pm 0.6 \\
1155 \pm 126\end{array}$ & $\begin{array}{c}\mathrm{RF}_{2} \\
14 \\
60.0 \pm 3.3 \\
148 \pm 12 \\
15.5 \pm 0.6 \\
973 \pm 83\end{array}$ & $\begin{array}{c}\mathrm{RB}_{2} \\
44 \\
42.6 \pm 4.4 \\
145 \pm 8 \\
14.1 \pm 0.6 \\
1055 \pm 49\end{array}$ \\
\hline $\mathbf{P}_{2}$ & $\begin{array}{l}\text { Family } \\
\text { No. of capsules } \\
\text { Mean germination }(\%) \\
\text { Mean seed weight } / \text { capsule } \\
\text { Mean } 100 \text { seed weight } \\
\text { Mean no. seeds/capsule }\end{array}$ & $\begin{array}{c}\mathrm{RF}_{1} \\
22 \\
89.3 \pm 2.0 \\
109 \pm 7 \\
12.8 \pm 0.7 \\
897 \pm 80\end{array}$ & $\begin{array}{c}\mathrm{B}_{2} \\
36 \\
41.3 \pm 5.1 \\
107 \pm 10 \\
13.7 \pm 0.5 \\
772 \pm 61\end{array}$ & $\begin{array}{c}\mathrm{B}_{2} \\
28 \\
42.2 \pm 5.3 \\
87 \pm 9 \\
12.0 \pm 0.7 \\
697 \pm 54\end{array}$ & $\begin{array}{c}\mathrm{P}_{2} \\
10 \\
15.8 \pm 6.0 \\
79 \pm 6 \\
11.7 \pm 1.1 \\
714 \pm 69\end{array}$ \\
\hline
\end{tabular}

Mean seed weights per capsule and mean one hundred seed weights are shown in $\mathrm{mg}$.

Table 4 Seed characters of hand-pollinated and open-pollinated capsules of Papaver rhoeas

\begin{tabular}{lcc}
\hline & \multicolumn{2}{c}{ Type of capsule } \\
\cline { 2 - 3 } Character & Hand-pollinated & Open-pollinated \\
\hline Mean germination $(\%)$ & $57.8 \pm 1.9$ & $63.3 \pm 4.0$ \\
Mean seed weight per capsule $(\mathrm{mg})$ & $134.3 \pm 3.8$ & $102.8 \pm 9.6$ \\
Mean hundred seed weight $(\mathrm{mg})$ & $14.4 \pm 0.2$ & $14.0 \pm 0.6$ \\
Mean number of seeds per capsule & $956 \pm 26$ & $747 \pm 67$ \\
\hline
\end{tabular}

Entries in the table are the means $( \pm S E$ ) of 314 hand-pollinated and 38 openpollinated capsules. 
less, these data provide no evidence that seed produced by hand-crossing is inferior to that produced by natural pollination.

\section{Estimation of the genetic parameters of family means}

Hierarchical analyses of variance were carried out on the germination data of each group of families of the same type (i.e. $F_{1}, F_{2}, B_{1}, B_{2}$ ) to test the homogeneity of reciprocals and crosses within them and to obtain an appropriate mean square (the highest significant mean square in the hierarchy, pooled with any items above it) from which the weight attached to their family means could be found. These preliminary analyses (data not shown) revealed that while the differences between reciprocal $F_{1}, B_{1}$ and $B_{2}$ family means were of the kind expected with maternal inheritance, only that between the pair of $\mathrm{B}_{1}$ families was significant $(P=0.002)$. Nevertheless, this suggested that it would be worthwhile fitting a model to these data which allows for this source of variation.

Modified scaling tests, in which the female parent of the families involved in each comparison is kept constant to remove maternal effects, were used to test for the presence of non-allelic interaction in the data (Mather \& Jinks, 1982). The results of these tests and their genetical expectation in the presence of non- allelic interaction are shown in Table 5. The significant negative value of the $t$-test for the $\mathrm{C}$ comparison indicates the presence of additive $\times$ additive interaction in these data and that the sign of $[i]$ is positive. Because, however, neither of the other comparisons departs significantly from zero, despite the fact that they also contain $[i]$, it appears that additive $\times$ dominance interaction is absent $([j] \cong 0)$ and the dominance $\times$ dominance interaction component, $[l]$, is of approximately equal magnitude, but opposite in sign, to $[i]$.

As these preliminary tests detected both maternal effects and non-allelic interaction in the data, a model of eight parameters (Barnes, 1968; Mather \& Jinks, 1982) was initially fitted to the family means by the usual weighted least squares procedure (Table 6). Because, however, the variance of the $\mathrm{P}_{2}$ family mean has only four degrees of freedom (a consequence of the procedure used to find the appropriate variance of this mean), the goodness of fit of a model to the data was assessed by an $F$-test, rather than the more usual $\chi^{2}$, as Werner (1984) has shown that a minimum of six degrees of freedom is required with the latter.

Two models gave a satisfactory fit to the data (Table 7). Although the magnitudes of the estimates differ between these models, they agree in indicating that the 'Shirley' and wild-type parents differ for genes that

Table 5 Modified scaling tests for non-allelic interaction in the presence of maternal effects

\begin{tabular}{lccc}
\hline Comparison & $\begin{array}{c}\text { Genetic } \\
\text { expectation }\end{array}$ & $\begin{array}{c}\text { Numerical value } \\
\text { of } t \text {-test }\end{array}$ & $P$ \\
\hline $\mathrm{A}=2 \mathrm{~B}_{1}-\mathrm{F}_{1}-\mathrm{P}_{1}$ & $\frac{1}{2}(-[i]-[l]+[j])$ & 0.1780 & $0.90-0.70$ \\
$\mathrm{~B}=2 \mathrm{~B}_{2}-\mathrm{RF}_{1}-\mathrm{P}_{2}$ & $\frac{1}{2}(-[i]-[l]-[j])$ & -1.1177 & $0.3-0.1$ \\
$\mathrm{C}=2 \mathrm{~F}_{2}-\mathrm{RB}_{1}-\mathrm{RB}_{2}$ & $-\frac{1}{2}[i]$ & -3.3947 & $0.01-0.001$ \\
\hline
\end{tabular}

Table 6 Eight parameter genetic model fitted to the family means of angular transformed germination percentages, and the weights and the degrees of freedom of the variances of the family means from which the weights were derived

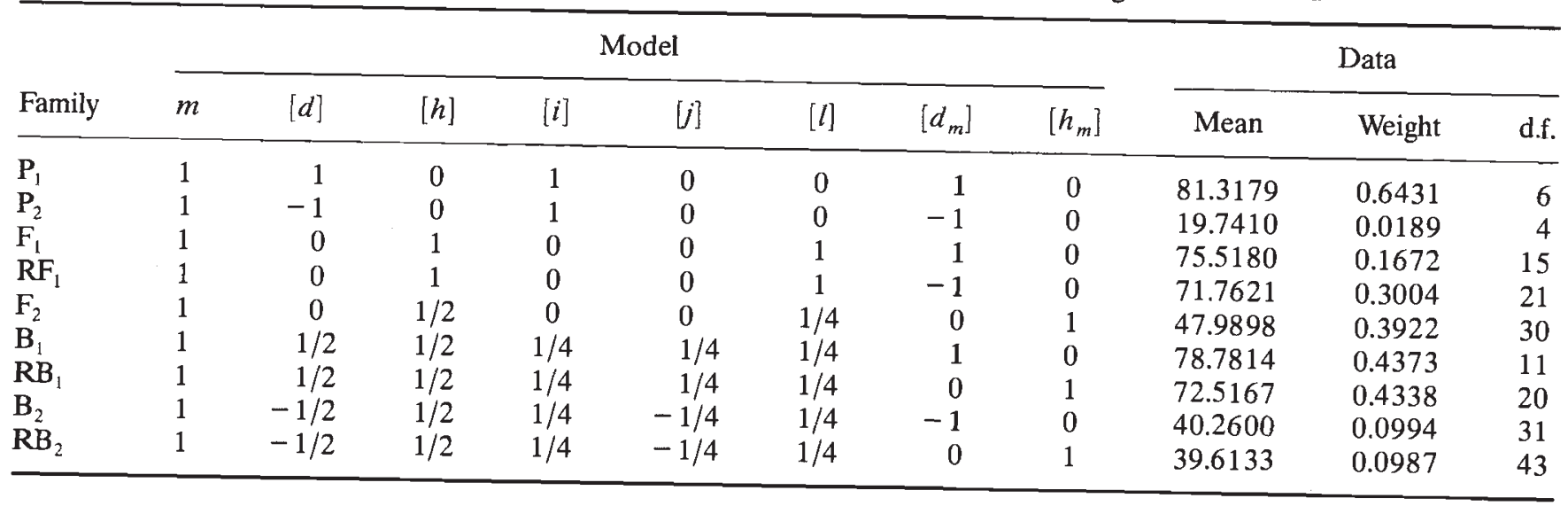


Table 7 Estimates of the genetical parameters $( \pm S E)$ of the family means

\begin{tabular}{ccc}
\hline & \multicolumn{2}{c}{ Model } \\
\cline { 2 - 3 } Component & 1 & 2 \\
\hline$m$ & $16.6 \pm 8.5$ & $35.2 \pm 5.1$ \\
{$[d]$} & $34.2 \pm 2.1$ & $27.9 \pm 3.2$ \\
{$[h]$} & $89.8 \pm 18.2$ & $38.4 \pm 5.8$ \\
{$[i]$} & $30.7 \pm 8.8$ & $18.5 \pm 6.4$ \\
{$[j]$} & - & $19.3 \pm 6.8$ \\
{$[l]$} & $-33.4 \pm 10.8$ & - \\
{$\left[h_{m}\right]$} & $-5.2 \pm 1.9$ & $-5.2 \pm 1.9$ \\
$P$ & 0.29 & 0.16 \\
\hline
\end{tabular}

Bottom row of the table shows the probability, $P$, obtained from the goodness of fit $F$-test of the model to the data.

display additive effects, substantial dominance in the direction of no dormancy and non-allelic interaction of the additive $\times$ additive kind; they also agree in indicating the presence of a small maternal dominance component, which is opposite in sign to the corresponding zygotic component. The models disagree, however, in respect of the remaining epistatic components. The first indicates the presence of substantial dominance $\times$ dominance interaction whereas the second suggests that the additional interaction is of the additive $\times$ dominance kind. Because the scaling tests (Table 5), although based on fewer data, gave clear evidence of the presence of both additive $\times$ additive and of dominance $\times$ dominance epistasis, but no additive $\times$ dominance epistasis, the first model, which showed a marginally better fit to the data than the second, must be preferred on the grounds of consistency. As the sign of the estimate of $[l]$ is opposite to that of $[h]$ in this model, the genes for which the 'Shirley' and wild-type parents differ appear also to display epistasis of the duplicate type.

There are two further points that need to be made about these results. First, although the estimate of $m$ in the first model is not significantly different from zero, it has been retained for logical reasons (an estimate of zero would indicate that the parents have no genes in common for the character in question) and because no model omitting this parameter gave a satisfactory fit to the data. Secondly, the distribution of the data, particularly in the $\mathrm{P}_{1}, \mathrm{P}_{2}, \mathrm{~F}_{1}$ and $\mathrm{B}_{1}$ families was very nonnormal, even after angular transformation. The use of the analysis of variance and associated procedures in these circumstances is, perhaps, questionable. While there may be little doubt about the broad conclusions we have drawn from the analysis of the results of this experiment, it might be prudent to exercise some caution in placing too much weight on the detail.

\section{Discussion}

The genetical analysis of angiosperm seed characters is complicated by the fact that each seed is, in general, composed of three types of tissue, the seed coat of diploid maternal origin, the endosperm, composed of one paternal and a variable number of maternal genomes, and the diploid embryo. The ripe seed of poppies, however, lacks an endosperm, so that it is necessary to consider only the maternal seed coat and the filial embryo. Seed dormancy is usually considered to have evolved to prevent all of the seed of a population germinating when conditions are only transiently favourable; if so, the character, having been subject to directional selection for dormancy, might be expected (see below) to display both maternal and filial genetic control, and dominance in the direction of high dormancy. Because of the complexity of the inheritance of seed characters, it is necessary to employ a breeding design which involves not less than three generations of relatives if maternal and filial genetic effects are to be separated. Although there is a considerable literature on the genetics of seed dormancy and other seed characters (see Platenkamp \& Shaw (1993) and references therein), few studies meet this requirement. Nevertheless, such evidence as exists is consistent with the expectation of both filial and, in particular, maternal control of seed dormancy, and that dormancy is dominant to non-dormancy (Garbutt \& Witcombe, 1986).

The results presented here are clearly not consistent with these expectations in that genetic control of dormancy in this 'Shirley' $\times$ wild-type cross appears to be chiefly filial, rather than maternal, and that dominance is in the direction of no dormancy. The history of the 'Shirley' cultivar, however, suggests that the genetic architecture of the character in this cross may differ from that expected in wild poppies. Thus, the cultivar originated from seed taken from a single flower, which had a very narrow white edge on each of its four petals, on an otherwise wild-type plant, by the Rev. W. Wilks, who was Vicar of the parish of Shirley, near Croydon, Surrey, in 1880 (Wilks, 1900). Subsequently, by selective breeding, he succeeded in obtaining the range of flower colours by which the variety is recognized today. Assuming that the seed of the original plant was no less dormant than that of presentday wild plants, there must have been intense, directional selection in the early generations of this breeding programme for reduced dormancy. Indeed, as seed of 
the new variety was being widely distributed by 1900 , the response to selection for no dormancy must have been rapid. A variety whose seed had poor germination would have been of limited interest to gardeners and horticulturists.

Mather $(1953,1960,1966,1973,1983)$ has argued that the genetic architecture of a character reflects the type of selection imposed on that character. On this theory, characters which have been subject to directional selection are expected to display strong unidirectional dominance together with non-allelic interactions of the duplicate type. Seed dormancy in the cross 'Shirley' $\times$ wild-type displays exactly the kind of genetic architecture that Mather's theory leads us to expect. The sign of the small maternal dominance component, $\left[h_{\mathrm{m}}\right]$, is, however, opposite to that of $[h]$, which suggests that the chief impact of this directional selection has been on the filial, rather than the maternal, tissue of the seed.

A response to selection for no dormancy during the breeding of the 'Shirley' variety could not have been obtained in the absence of genetic variation for this character. The source of this variation is not obvious. There is little evidence of heritable variation in material of natural origin in $P$. rhoeas. More is available from $P$. dubium, however, which, although a predominantly self-pollinating species (Humphreys \& Gale, 1974), has a very similar ecology to $P$. rhoeas and the two species are not infrequently found growing together. Although a small proportion of the seed of both species will germinate in the field, whenever conditions are favourable at almost any time of the year, most plants originate from seed that has germinated either in late autumn or early spring. Autumn germinators nearly always die during a severe winter (McNaughton \& Harper, 1964) but in mild winters a substantial proportion survives and contributes to the adult population of flowering plants in the following summer. Arthur et al. (1973) have shown that surviving autumn germinators have a very considerable advantage over their spring germinators in terms of seed output. It might be supposed, therefore, that germination time is an important ecological character which would exhibit heritable variation. Arthur et al. (1973) showed, however, that the proportion of seed germinating in the autumn among the descendants of 20 autumn germinators was, on average, no different from that of 20 plants that had descended from spring germinators and concluded that selection had favoured plants capable of producing a mixture of the two kinds of seeds.

Afzal (1974) investigated the effect of five successive generations of selection for low dormancy in three lines maintained by selfing which originated from the same natural population of $P$. dubium as that investi- gated by Arthur et al. (1973). In each generation, each line was maintained from seed that had been incubated at $2-5^{\circ} \mathrm{C}$ for 7 days. The percentage germination of the seed of one of these lines, when incubated at low temperature, was 84.4 per cent compared with 30.8 per cent for the unselected control. The germination percentage of the seed of the other two lines, however, was significantly lower than that of the unselected control. These results suggest that the amount of genetic variation in natural populations for seed dormancy must be quite low.

Rapid loss of seed dormancy is not the only feature of Wilks's breeding programme. Thus, as mentioned earlier, 'Shirley' poppies originated from the seed of a single capsule of a flower that had white edging on each of the four petals. Wilks (1900) tells us that in the following year 'out of perhaps 200 plants, I had four or five on which all the flowers were white edged'. A population founded on such a small number of plants must have a correspondingly small effective size, an effect which presumably was further reduced by selection, first for white-edged petals and later for flowers whose petals had a white centre and a range of petal colours. Newton (1929) and Philp (1933) showed that flower colour in wild $P$. rhoeas is determined by eight factors which fall into three linkage groups, six of which appear to be involved in the difference between wild-type poppies and those of the 'Shirley' variety. Flower colour variants are exceedingly rare in natural populations of poppies; in 20 years of work we have obtained only one obvious variant from two partially inbred families. In both cases flowers were pure white, which suggested a single gene may be involved which determines an enzyme required early in the biosynthesis of the flower colour pigments. The fact that Wilks appeared to find six flower colour genes in a closed population whose effective size must have been very small during the 20 years that it took to breed the 'Shirley' variety, is remarkable and suggests that the mutation rate was much higher in this population than is normal. McDonald (1995) has recently drawn attention to the fact that mutations induced by the insertion of transposable elements into coding and regulatory nucleotide sequences do not always arise at a low and constant rate, but often originate in 'transpositional bursts', in which rates can be as high as $10^{-3}$ to $10^{-2}$ and that these bursts appear to be caused by inbreeding and other forms of genomic or environmental stress. As the inbreeding in Wilks's material must have been quite severe, the flower colour mutants may have arisen in this way. For the same reason, it is possible that the loss of seed dormancy resulted from mutation, rather than from the selection of genes existing in the foundation plants. Although there is no evidence in our 
$F_{2}$ and $B_{2}$ families of the segregation of genes of major effect with respect to seed dormancy, the very large amount of uncontrollable variation between capsules, plants and crosses may have obscured such segregation. If this rather speculative hypothesis is correct, it should be somewhat easier to detect an association between genes that control seed dormancy and the alleles of other single genes, such as those of the selfincompatibility gene, than if seed dormancy is determined by many genes. An investigation of this possibility is described in a later paper (Lane \& Lawrence, 1995).

\section{Acknowledgements}

This work was supported by the award of an NERC studentship to M.D.L. and an NERC research grant to M.J.L. which are gratefully acknowledged.

\section{References}

AfZAL, M. 1974. Population Genetics of Papaver Species. Ph.D. Thesis, University of Birmingham.

ARTHUR, A. E., GALE, J. S. AND LAWRENCE, M. J. 1973. Variation in wild populations of Papaver dubium. VII. Germination time. Heredity, 30, 189-197.

BARNES, B. W. 1968. Maternal control for heterosis for yield in Drosophila melanogaster. Heredity, 23, 563-572.

CAMPBELL, J. M. AND LAWRENCE, M. J. 1981. The population genetics of the self-incompatibility polymorphism in Papaver rhoeas. II. The number and frequency of $S$-alleles in a natural population (R106). Heredity, 46, 81-90.

GARBUTT, K. AND WITCOMBE, J. R. 1986. The inheritance of seed dormancy in Sinapis arvensis. L. Heredity, 56, 25-31.

harper, J. L. 1977. Population Biology of Plants. Academic Press, London.

HARPER, J. L. AND McNAUGHTON, I. H. 1960. The inheritance of dormancy in inter- and intraspecific hybrids of Papaver. Heredity, 15, 315-320.

HUMPHREYS, M. O. AND GALE. J. S. 1974. Variation in wild populations of Papaver dubium. VIII. The mating system. Heredity, 33, 33-42.
LANE, M. D. 1990. The Population Genetics of the Selfincompatibility Polymorphism in Papaver rhoeas. Ph.D. Thesis, University of Birmingham.

LANE, M. D. AND LAWRENCE, M. J. 1995. The population genetics of the self-incompatibility polymorphism in Papaver rhoeas. X. An association between incompatibility genotype and seed dormancy. Heredity, 75, 92-97.

LAWRENCE, M. J. AND FRANKLIN-TONG, v. E. 1994. The population genetics of the self-incompatibility polymorphism in Papaver rhoeas. IX. Evidence of an extra effect of selection acting on the $S$-locus. Heredity, 72, 353-364.

LAWRENCE, M. J. AND O'DONNELL, S. 1981. The population genetics of the self-incompatibility polymorphism in Papaver rhoeas. III. The number and frequency of $S$ alleles in two further natural populations (R102 and R104). Heredity, 47, 53-61.

McDonAld, J. F. 1995. Transposable elements: possible catalysts for organismic evolution. Trends Ecol. Evol., 10, 123-126.

McNAUGHTON, I. M. AND HARPER, J. L. 1964. Biological flora of the British Isles. No. 99. Papaver L. J. Ecol., 52, 767-793.

MATHER, K. 1953. The genetical structure of populations. Symp. Soc. Exp. Biol., 7, 66-95.

MATHER, K. 1960. Evolution in polygenic systems. Evoluzione e Genetica, pp. 131-152. Academia Nazionale dei Lincei, Rome.

MATHER, K. 1966. Variability and selection. Proc. R. Soc. B, 164, 328-340.

MATHER, K. 1973. Genetical Structure of Populations. Chapman \& Hall, London.

MATHER, K. 1983. Response to selection. In: Ashburner, M., Carson, H. L. and Thompson, J. N., Jr. (eds) The Genetics and Biology of Drosophila, vol. 3c. pp. 155-221. Academic Press, London.

MATHER, K. AND JINKS, J. L. 1982. Biometrical Genetics, 3rd edn. Chapman \& Hall, London.

NEWTON, W. C. F. 1929. The inheritance of flower colour in Papaver rhoeas and related forms. J. Genet., 21, 389-404. PHILP, J. 1933. The genetics of Papaver rhoeas and related forms. J. Genet., 28, 175-203.

PLATENKAMP, G. A. J. AND SHAW, R. G. 1993. Environmental and genetical maternal effects on seed characters in Nemophila menziesii. Evolution, 47, 540-555.

WERNER, P. 1984. The Consequences of Pollen Irradiation in Nicotiana rustica. Ph.D. Thesis, University of Birmingham.

wILKs, w. 1900. The Secretary. J. R. Hort. Soc., 25, 160-162. 